Article

\title{
The Impact of Global Warming on Wind Energy Resources and Ramp Events in Japan
}

\author{
Masamichi Ohba $\mathbb{D}$ \\ Central Research Institute of Electric Power Industry (CRIEPI), Environmental Science Research Laboratory, \\ 1646 Abiko, Abiko-shi, Chiba 270-1194, Japan; oba-m@criepi.denken.or.jp; Tel.: +81-070-5577-4802
}

Received: 22 April 2019; Accepted: 11 May 2019; Published: 13 May 2019

\begin{abstract}
This study investigated the impact of global warming on Japanese wind energy resources and their short-term variations using the large ensemble d4PDF dataset, which consists of dynamically downscaled historical and $+4 \mathrm{~K}$ future climate projections. The capacity factor under the future and present climate was estimated from an idealized power curve based on hourly near-surface wind speeds. The $+4 \mathrm{~K}$ warming future climate projections showed significant changes in wind energy resources that varied both regionally and seasonally. The wind energy potential was projected to slightly increase (decrease) from winter to spring over northern (southern) Japan and decrease from summer to autumn over most of Japan. The projected annual production decreased by about $\sim 5 \%$ over Japan in response to climate change. The frequency of wind ramp events also decreased in the latter seasons. The relationship to synoptic weather was investigated using self-organizing maps, whereby weather patterns (WPs) over the region in the present and future $+4 \mathrm{~K}$ climate were classified for a two-dimensional lattice. Future probabilistic projections of WPs under the global warming scenario showed both increases and decreases in the frequency of different WPs, with corresponding advantages and disadvantages for wind power generation with regard to future changes in capacity factors in Japan. The importance of these frequency changes on the total change was further assessed by separating the dynamical and thermodynamic contributions.
\end{abstract}

Keywords: capacity factor; wind energy resource; climate change; self-organizing maps; weather patterns; synoptic circulation; constructed circulation analogs

\section{Introduction}

Observed and projected climate changes have raised the need to increase renewable energy production in future decades. Wind power is one of the fastest-growing renewable energy technologies, with global cumulative wind power capacity reaching $~ 540$ GW by the end of 2017 and $\sim 4 \%$ of global electricity currently being produced by wind energy. After the Fukushima Daiichi nuclear power plant accident in early 2011, the Japanese government decided to promote renewable energy resources [1]. While wind energy currently represents a relatively minor proportion of Japan's energy production, it will be significantly increased in the next few decades. By FY2030, the Japanese Wind Power Association aims to introduce approximately $36 \mathrm{GW}$ of electricity production in Japan from onshore and offshore wind power, with a further increase expected in the future.

Wind energy production may be influenced by climate change as this will alter the spatial and temporal characteristics of current wind patterns through changes in background climatological conditions and synoptic-scale variability [2]. Since wind energy scales have the cube of wind speed, slight changes in wind profiles can significantly affect the extractable energy output. Changes in wind availability will therefore have a substantial impact on the cost of wind energy production. In this context, climate models are a crucial and powerful tool for estimating wind resources in different climate situations. Several studies have already assessed the impacts of global warming on wind energy 
resources at local and global scales [3-9]. Future projections from climate models show wind speeds changing heterogeneously, with wind resource potential significantly increasing or decreasing in some areas $[3,9,10]$. Such studies have focused primarily on changing wind speed or density and estimated energy output using idealized power curves to discuss climate change's impact on energy potential.

Sudden large increases and decreases in wind energy output over a short period, caused by wind speed fluctuations, are known as wind ramp events and are one of the dominant problems in wind energy [11-15]. These occur often in Japan because of geographic/climatological conditions that affect the load generation balance of the electricity supply. Since wind ramp events decrease the stability of the power grid, they must be balanced by other power sources, so future changes in wind ramp frequency are also of great concern. Previous studies summarizing wind power in Japan's current climate and the impact of synoptic weather patterns have shown that Japan's mid-latitudinal location produces a strong seasonal cycle in wind resources and their variability [11-13]. Wind energy increases in winter and decreases in summer due to higher mean wind speeds associated with the winter monsoon (i.e., zonal pressure gradients). A primary mechanism for strong ramp events during winter is extratropical cyclones, low-pressure storm systems that tend to impact Japan from the west and southwest along prevailing storm tracks. Interannual variations in wind power generation and ramp frequency are also correlated with the Siberian High [11]. In addition, wind speeds tend to be higher during the day than at night due to temperature gradients and this effect is intensified in summer. Current wind resources and capacity factors in Japan have also been estimated using meteorological models [16-22].

Future changes in East Asian climates are particularly difficult to project since they depend on simulated sea surface temperature (SST) anomalies in the Indo-Pacific sector [23-25] that are not fundamentally understood and strong model diversity still exists both for the future mean climate [26] and its variations $[27,28]$. Ongoing research should push these boundaries to better understand future changes in wind energy resources and their associated dynamic mechanisms. Incorporating this subject into the evaluation of how wind energy resources will change in a global warming context can cross interdisciplinary boundaries between climate science and power engineering.

In this study, we utilized very large state-of-the-art ensemble simulations to predict the local geographic distribution of future changes in wind energy resources in Japan under $+4 \mathrm{~K}$ global warming conditions. In addition, to better understand the meteorological cause of these changes, we applied weather classification using machine learning to examine the impact of climate change on the relationships between synoptic-scale weather patterns (WPs) and local-scale wind speeds in Japan.

\section{Data and Methods}

\subsection{Data}

We used atmospheric simulation data for historical and projected climates taken from the Database for Policy Decision Making for Future Climate Change (d4PDF; [26]). This consists of outputs from general circulation models (d4PDF-GCM) that are dynamically downscaled for the Japanese region using a regional climate model (d4PDF-RCM) with horizontal grid spacings of $60 \mathrm{~km}$ and $20 \mathrm{~km}$, respectively. The 40-member historical simulations (1951-2010) and the 60-member $+4 \mathrm{~K}$ future climate projections (employing 6 cases for each 10-member ensemble, 2051-2110) were used to analyze the impact of climate change. In $\mathrm{d} 4 \mathrm{PDF}$, the amplitude of the $+4 \mathrm{~K}$ warming is kept constant throughout the 60-yr integration. Details of the experimental setup for these simulations can be found in [26]. The ensemble members were obtained from the perturbed initial and lower boundary conditions of a $60-\mathrm{km}$ GCM. For the $+4 \mathrm{~K}$ simulations, climatological SST warming patterns obtained from six Coupled Model Intercomparison Project Phase 5 (CMIP5) models (CCSM4, MIROC5, MPI-ESM-MR, HadGEM2-AO, GFDL-CM3, and MRI-CGCM3) were added to the observational SST after removing the long-term trend component. Warming patterns were obtained from the SST difference between RCP8.5 simulations minus historical experiments. 
Although we used the 20-km resolution grid data, previous studies (e.g., [9]) have concluded that the coarse horizontal resolution of global/regional climate models does not undermine their utility for assessing wind resource variability. To validate and compare the climatic features simulated in d4PDF, we also used regional downscaling data (DSJRA-55, [29]) based on the Japanese 55-year Reanalysis (JRA-55, [30]) for initial and boundary conditions for the period 1958-2012; the horizontal resolution of the DSJRA-55 data was $5 \mathrm{~km}$.

\subsection{Power Curve}

Wind turbines only generate electricity within the cut-in and cut-out wind speeds. There is no simple linear response between mean annual wind speed and power output. To estimate the wind power resources around Japan, we used a typical wind farm power curve (Figure 1; [31]) instead of manufacturer's power curves [8,32]. Although the power curves specified by manufacturers are generally used to convert wind speed into electricity output, as reported by [31], the power curve for an individual turbine should be revised if the power output from a whole wind farm is required. This is probably due to the wake effects of neighboring turbines within the wind farm that cause a decreased shut-down wind speed with gentler full-power transition/shut-down slopes.

Simulation of wind energy resources using surface wind speeds with model or reanalysis data has been conducted in many previous studies $[8,9,33]$, showing that the use of simulated wind speeds in reanalysis can provide relatively accurate regionally integrated wind energy estimates $[33,34]$. As the surface wind speed data in the $\mathrm{d} 4 \mathrm{PDF}$ are projected at $10 \mathrm{~m}$ above ground, they must be extrapolated to the wind turbine hub height. Wind speeds within the boundary layer are directly proportional to height from the surface up to $100-150 \mathrm{~m}$ due to surface friction. We used wind speeds at $80 \mathrm{~m}$ height (typical hub heights are 60-100 m), defined as follows:

$$
v(z)=v\left(z_{0}\right)\left(\frac{z}{z_{0}}\right)^{\alpha}
$$

where $v(z)$ is wind speed at height $z$ and $\alpha$ denotes the shear coefficient, a function of surface topology that varies with land cover. For $v\left(z_{0}\right)$, we used hourly $10 \mathrm{~m}$ wind speeds. For simplicity, we used a value of $1 / 7$ following previous studies $[8,9]$. The obtained $v(z)$ was then used to estimate the energy generation from the power curve (Figure 1). Annual/seasonal wind-power capacity factors (the wind-power production divided by the installed wind-power capacity) were obtained from the annual/seasonal energy output divided by the theoretical maximum output, assuming operation at the rated (maximum) power during the entire period. We used "per unit" (p.u.) instead of percent.

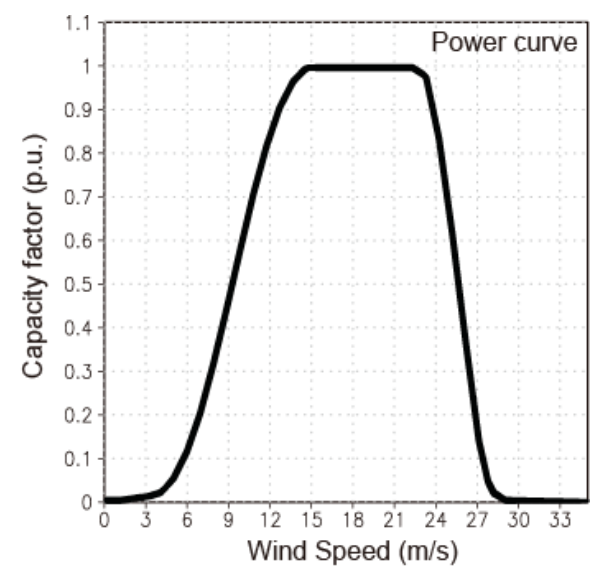

Figure 1. Wind farm power curve used in this study. 


\subsection{Self-Organizing Maps}

Generally, synoptic WPs associated with large-scale circulation are important to our understanding of wind energy generation and variability as they affect the statistics of wind speeds near the surface [35-37]. For example, there are clear relationships between wind power variability and classified WPs [11,36]. Previous studies suggest that wind energy generation varies with various meteorological phenomena, such as the evolution of synoptic-scale weather systems, at all scales. In this context, wind energy resources in Japan can also be mainly linked to synoptic WPs located in East Asia.

Artificial neural network learning mechanisms can be efficient tools for establishing links between various WPs and their impacts on local weather. Self-organizing maps (SOMs; [38]) are one of the most widely used nonlinear analysis techniques. This is a pattern recognition technique through which a powerful visualization is obtained by projecting high-dimensional data onto a visually interpretable two-dimensional map. The classification of WPs using SOMs is useful for identifying complicated non-linear interrelationships among weather and climate factors [39] and can potentially help identify complicated nonlinear interrelationships among synoptic-scale WPs associated with wind energy production.

To investigate future changes in WP frequency (and their relationship with energy resources), we applied the SOM technique to six-hourly values of sea-level pressure (SLP) derived from d4PDF and projected onto regularly arranged two-dimensional arrays. Each element in the array was denoted as a node with one reference vector. We used a $20 \times 20$ grid SOM with 400 reference vectors, each representing a generalized pattern of input vectors. In general, the map size should be moderate and both the calculation efficiency and the representation of patterns should be considered in order to extract all characteristic patterns. We selected a map size based on sensitivity tests. The SOM projection process is summarized in [28]; here we trained a SOM from either the present and future climate simulations. When used in other studies, this approach is often termed a "master SOM" [40,41]. The total number of input vectors was about 2,160,000 (4 times per day $\times 90 / 91$ days $\times 60$ years $\times 100$ ensembles).

An additional cluster analysis is often employed to fully exploit important patterns [42-44]. We clustered the SOM nodes into groups according to Ward's hierarchical clustering method [45] that seeks cluster pairs whose fusion results in a minimum Euclidean distance. The SOM was constructed for SLP in the historical and future simulations simultaneously.

\subsection{Separation of Dynamical and Thermodynamic Contributions by Circulation Analogs}

To gain further understanding, we tried to separate the impact of future changes in wind energy resources into dynamical and thermodynamic contributions. Changes in the intensity of wind generation can also be attributed to changes in the horizontal and vertical temperature distribution via alterations in the momentum flux. We confirmed the physical mechanisms underlying these changes in terms of the roles of dynamics (atmospheric circulation changes in the absence of radiatively induced changes in wind energy generation) and thermodynamics (changes in properties such as vertical temperature profile, sea ice, and snow depth on the land in the absence of atmospheric circulation changes).

Projected changes in climate are predominantly attributed to dynamic (atmospheric motion) and thermodynamic (temperature warming and moisture content) changes. We tried to separate these components for wind power change by using the SOM. The changes in wind energy potential between the future and present climate can be approximately expressed by using the SOM WP classification:

$$
\begin{aligned}
\delta W E=W E^{F c}-W E^{P c} \fallingdotseq \frac{1}{T} \sum_{i=1}^{n} E_{i}^{F c} f_{i}^{F c}-\frac{1}{T} \sum_{i=1}^{n} E_{i}^{P c} f_{i}^{P c} \\
\fallingdotseq \frac{1}{T} \sum_{i=1}^{n} E_{i}^{F c P c}\left(f_{i}^{F c}-f_{i}^{P c}\right)+\frac{1}{T} \sum_{i=1}^{n}\left(E_{i}^{F c}-E_{i}^{F c}\right) f_{i}^{F c P C},
\end{aligned}
$$


where $i$ is the SOM node number ( $n=400$ in this study), the superscripts $P_{c}(F c)$ denote a value obtained from present (future) climate, $F_{c} P c$ denotes the mean value between present and future climate, $E$ represents the node mean values of the wind energy generation pattern (spatial distribution) corresponding with the WPs, $f$ is the occurrence frequency of WP for each SOM node, and $T$ is the total times (i.e., $T=\sum_{i=1}^{n} f_{i}$ )

The first term represents the impact of WP frequency changes while the second shows the integrated impact of future changes in wind energy generation under the same WP. The former is regarded as the dynamic effect of climate change impacts and the latter as the thermodynamic change. The dynamical contribution of climate change on the wind energy resources $\delta W E_{d y n}$ can be estimated by assuming the same wind energy but a different frequency, expressed as:

$$
\delta W E_{d y n}=\frac{1}{T} \sum_{i=1}^{n} E_{i}^{F c P c}\left(f_{i}^{F c}-f_{i}^{P c}\right),
$$

while the thermodynamic contribution $\delta W E_{t h r}$ is estimated by assuming the same frequency but a different wind energy, expressed as:

$$
\delta W E_{t h r}=\frac{1}{T} \sum_{i=1}^{n}\left(E_{i}^{F c}-E_{i}^{F c}\right) f_{i}^{F c P C} .
$$

This method is regarded as the SOM-compressed version of the constructed circulation analog method (CCA) [46,47] that is used to illustrate the dynamical contribution to surface variable anomalies. Such analog techniques have traditionally been used for statistical weather forecasting $[13,39]$. Hereafter this method is called SOM-CCA.

\section{Projected Changes in Wind Resources and Ramps in Japan}

We estimated the annual wind power production (resources) from hourly $80 \mathrm{~m}$ wind speeds (extrapolated from $10 \mathrm{~m}$ winds) using the d4PDF present climate simulation and DSJRA55 (Figure 2) with the power curve (Figure 1). High wind resources exceeding 0.5 p.u. were especially concentrated in the northeastern part of the Japanese Exclusive Economic Zone (EEZ; the limit within which wind energy development can legally happen). The overall features of the wind resources simulated in d4PDF agree with those in the reanalysis downscaling data, though some areas showed poor agreement. For example, the wind energy in d4PDF is lesser (larger) than that in DSJRA55 along the coastline to the offshore (onshore). This error was also seen in a mountainous region of central Japan with underestimated resources. We attributed these differences mainly to the low resolution (i.e., $20 \mathrm{~km}$ ) of the d4PDF-RCM and assumed that such errors would not significantly affect the future differences that were the focus of this study.

Regarding the projected future changes in wind resources around Japan (Figure 3), the $+4 \mathrm{~K}$ projection agreed with the general pattern when compared to the present climate simulations (not shown) but tended to have the greatest decrease in wind resource change for onshore areas of southwestern Japan and offshore areas of southern Japan. The resultant decrease in wind energy resources around Japan was consistent with a previous study [9]. While existing onshore wind farms are located in northeastern Japan, decreases in resources were more apparent on the Pacific side of western Japan and the Japan Sea side of central Japan. We also found large decreases in offshore wind energy resources in the southern part of the Japanese EEZ. 


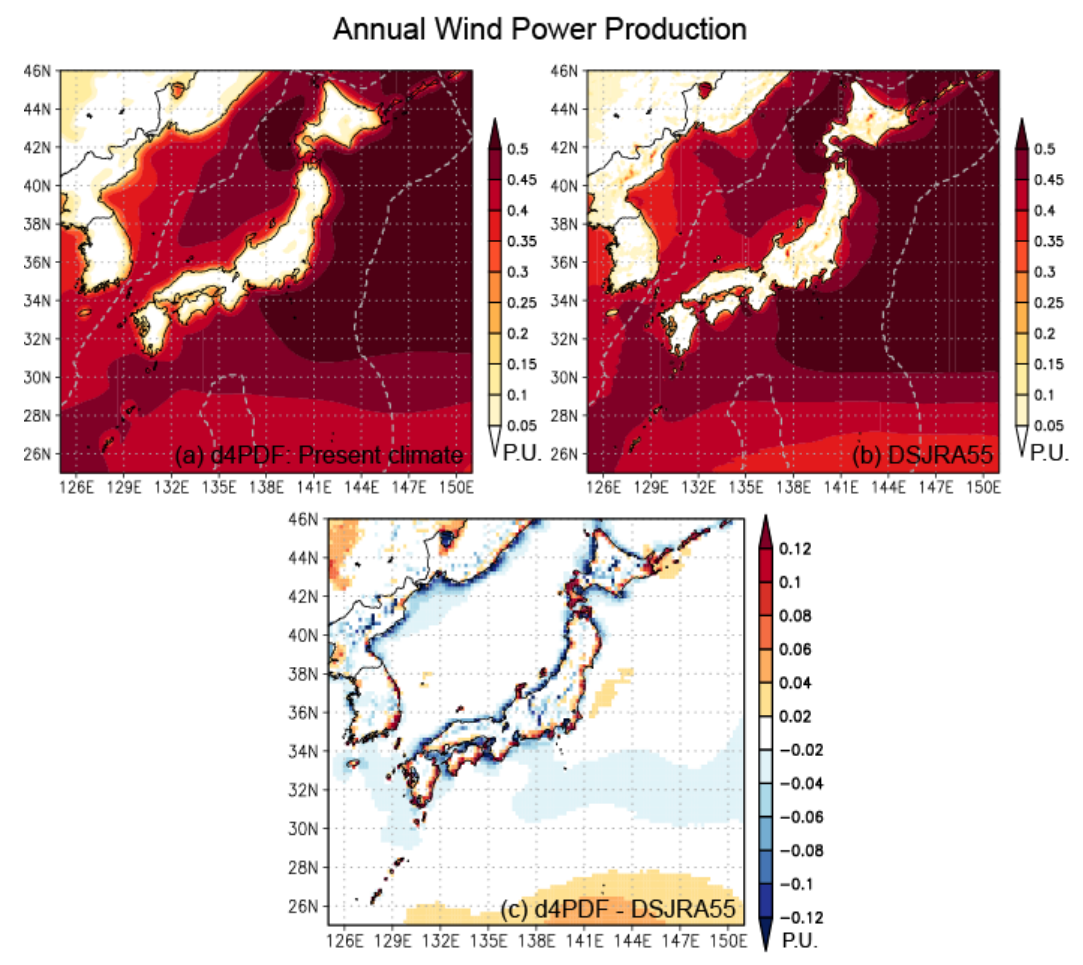

Figure 2. Annual capacity factor estimated by (a) d4PDF and (b) DSJRA55; (c) their difference. Gray dotted line represents the Japanese Exclusive Economic Zone (EEZ).

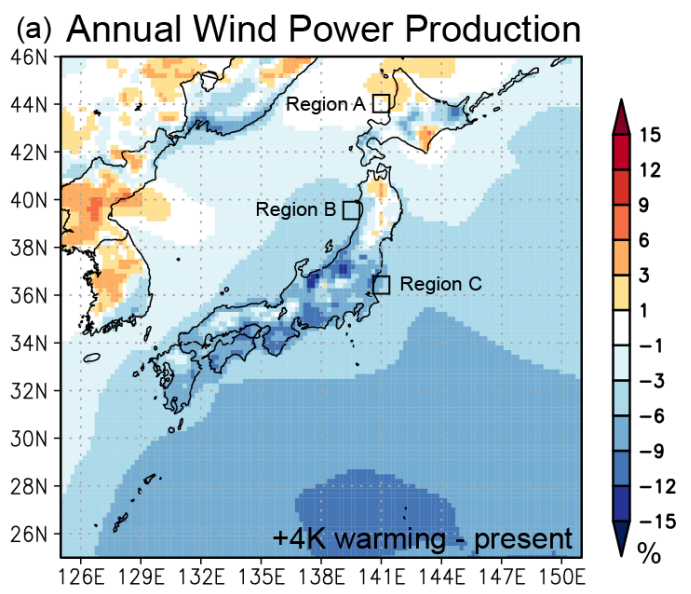

(b) WS10m Histogram: Future and Present

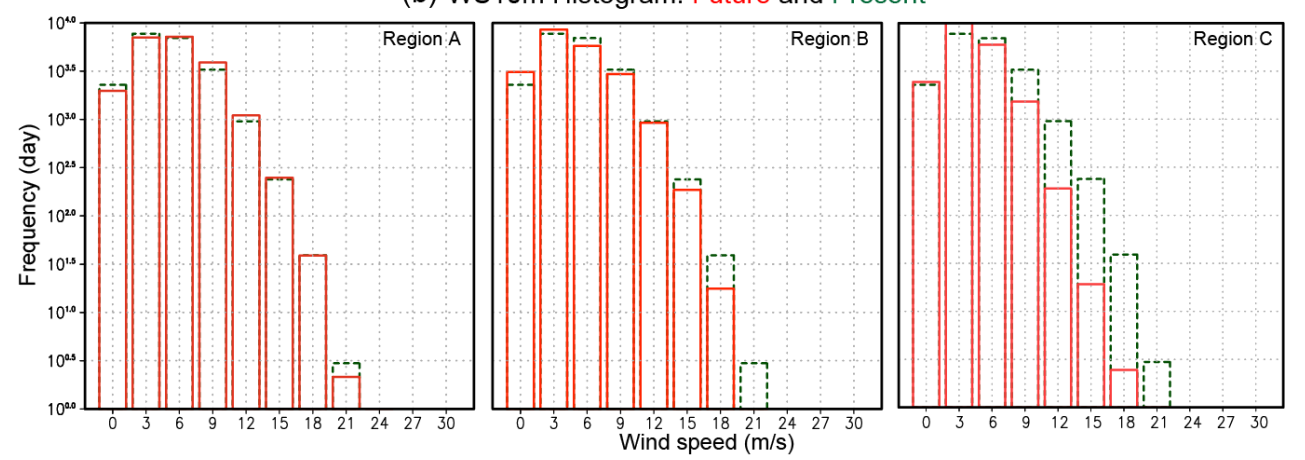

Figure 3. (a) Difference in annual capacity factors between future and present climate simulations. (b) Frequency distribution of daily wind speeds for present (green dash) and $+4 \mathrm{~K}$ future (red solid) climate simulations. 
Assessing the seasonal evolution of the future changes in wind resources and capacity factors in the present climate simulations (Figure 4) showed that the latter were larger during the boreal winter (compared to summer) because of seasonally strengthened northwesterly winds in relation to the East Asian winter monsoon. The response of future changes differed seasonally: from winter to spring, the wind energy potential was projected to slightly increase (especially over northern Japan), but from summer to autumn it may decrease in most parts of Japan. The area-averaged seasonal changes in wind energy potential for both climate simulations (Figure 5) clearly showed that wind resources decreased most during fall (September and October) and secondarily during winter. The peak reduction occurred in September, the second-most common month for typhoons in Japan (after August).

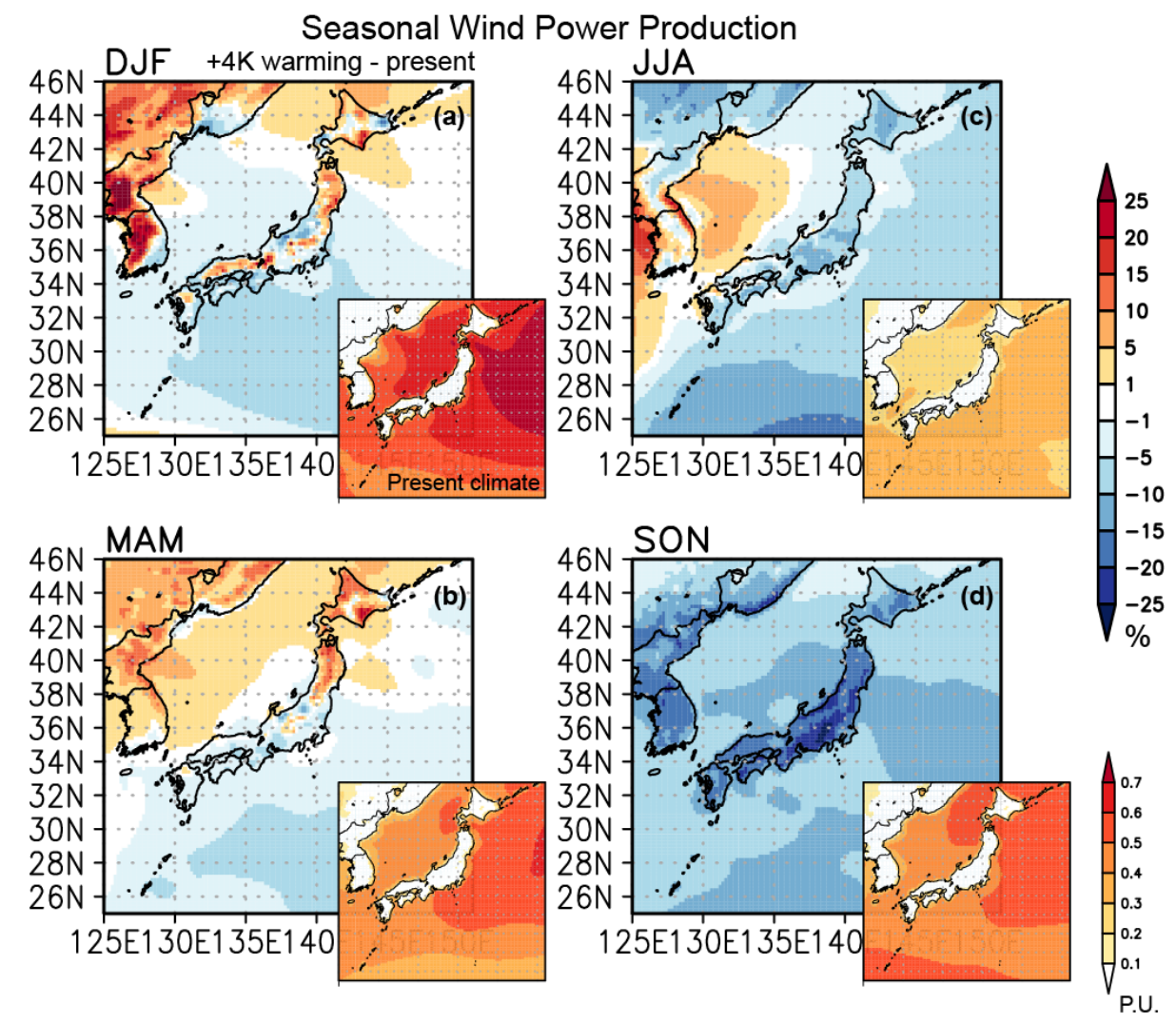

Figure 4. Difference in seasonal capacity factor between the future and present climate simulations for (a) December-January-February, (b) March-April-May, (c) June-July-August, and (d) September-OctoberNovember. Capacity factors in present climate simulations are also plotted for each season. 

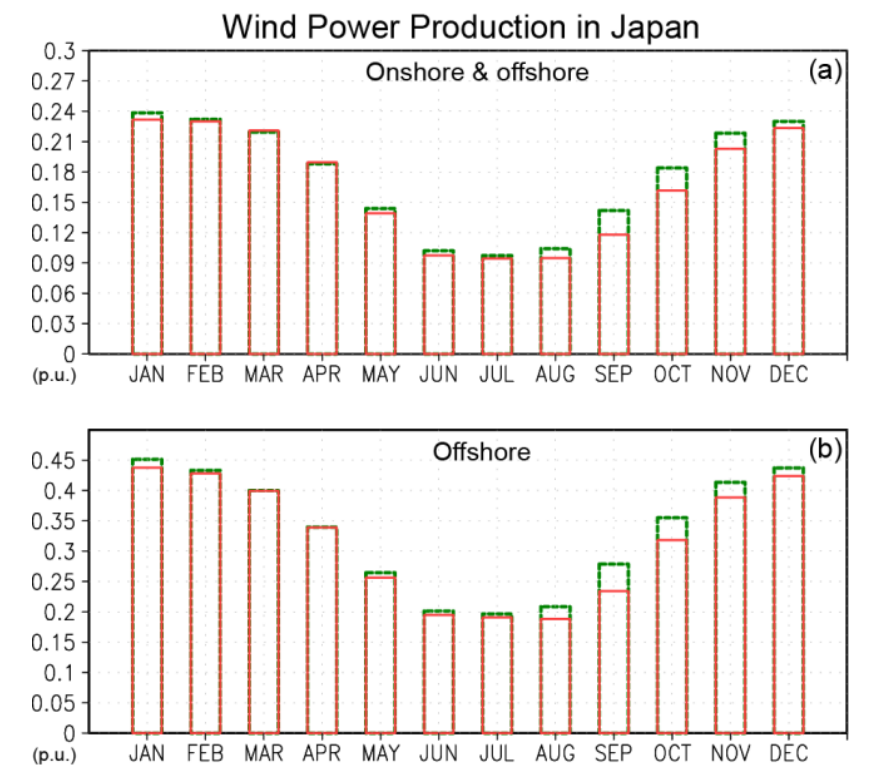

Figure 5. Seasonal evolution of capacity factors for present (dashed green) and future (solid red) climate simulations for (a) onshore and 20-km offshore of Japan's coastline and (b) 20-km offshore only.

In this study, we defined wind ramp events as $5 \mathrm{~m} / \mathrm{s}$ changes in wind speed within $\leq 6 \mathrm{~h}$; these can result in a $>30 \%$ change in the power output under $4-15 \mathrm{~m} / \mathrm{s}$ wind speed conditions (Figure 1 ). A positive (negative) change in wind speed was considered as a ramp-up (ramp-down) event. The former were more frequent (Figure 6), consistent with previous observational studies, perhaps due to asymmetry in diurnal wind speed changes between morning and afternoon [11]. Projected ramp-up and ramp-down events both decreased, though the latter was more apparent, especially in high mountain regions from central to eastern Japan. The simulated ramp frequency over land (Figure 6) was also consistent with an analysis of ramp events using actual wind power data [11]. The frequency of ramps over land showed a more comprehensive distribution compared with that over the ocean, which we attribute to local weather and the impact of terrain features that affect the frequency of ramps in addition to the movement/change in large pressure systems.

The occurrence frequency of simulated wind ramp events (Figures 7 and 8) was relatively low during the warm season (May-September) but higher during the cold season (October-April), consistent with observations in [11]. Spatial-seasonal evolutions of ramp-up and ramp-down frequency are consistent with each other. The approach of low/high pressure systems are the main cause of both events. From winter to spring, the future changes in wind ramps projected as inhomogeneous spatial patterns. During winter, wind ramps were decreased (increased) especially over the northern (western) part of Japan. However, in summer to autumn these experienced a decrease in most parts of Japan, most apparently during fall. 


\section{Annual Wind Ramp events}

(a) Ramp up: Climatology

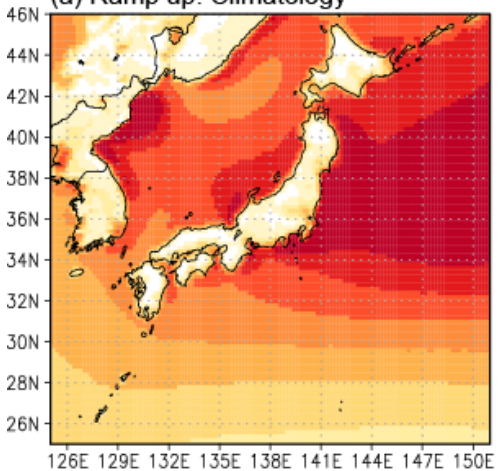

(b) Ramp down: Climatology

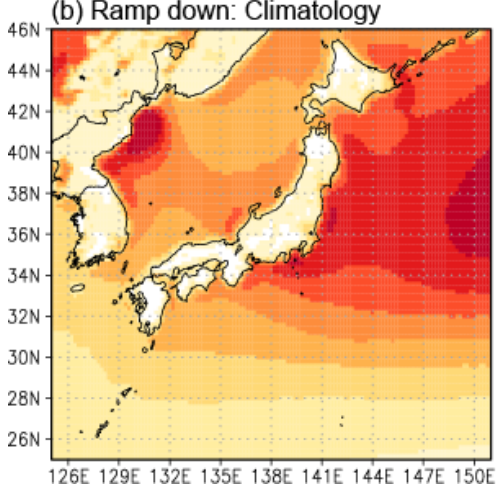

(c) Ramp up: $+4 \mathrm{~K}$ - present

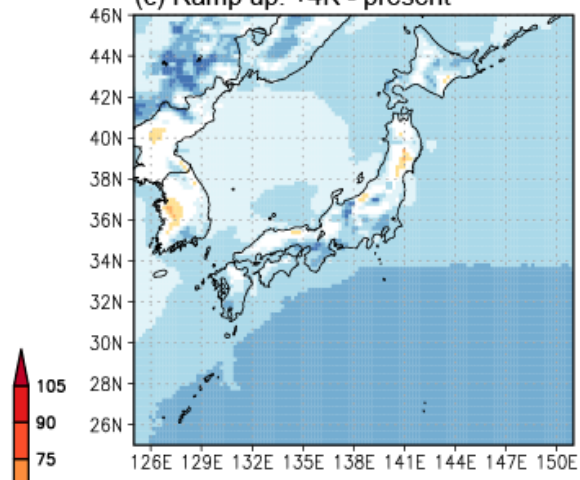

60 (d) Ramp down: $+4 \mathrm{~K}$ - present

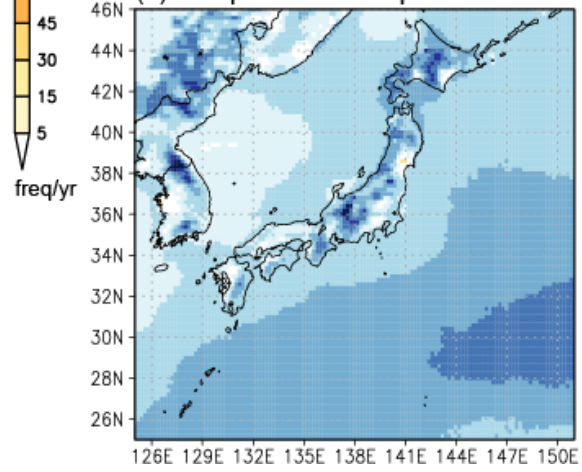

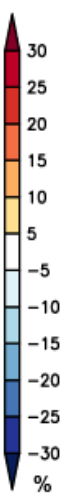

Figure 6. Annual frequency of wind ramp events in present climate simulations for (a) ramp-up and (b) ramp-down situations, and differences in frequency occurrences between future and present climate simulations for (c) ramp-up and (d) ramp-down situations.

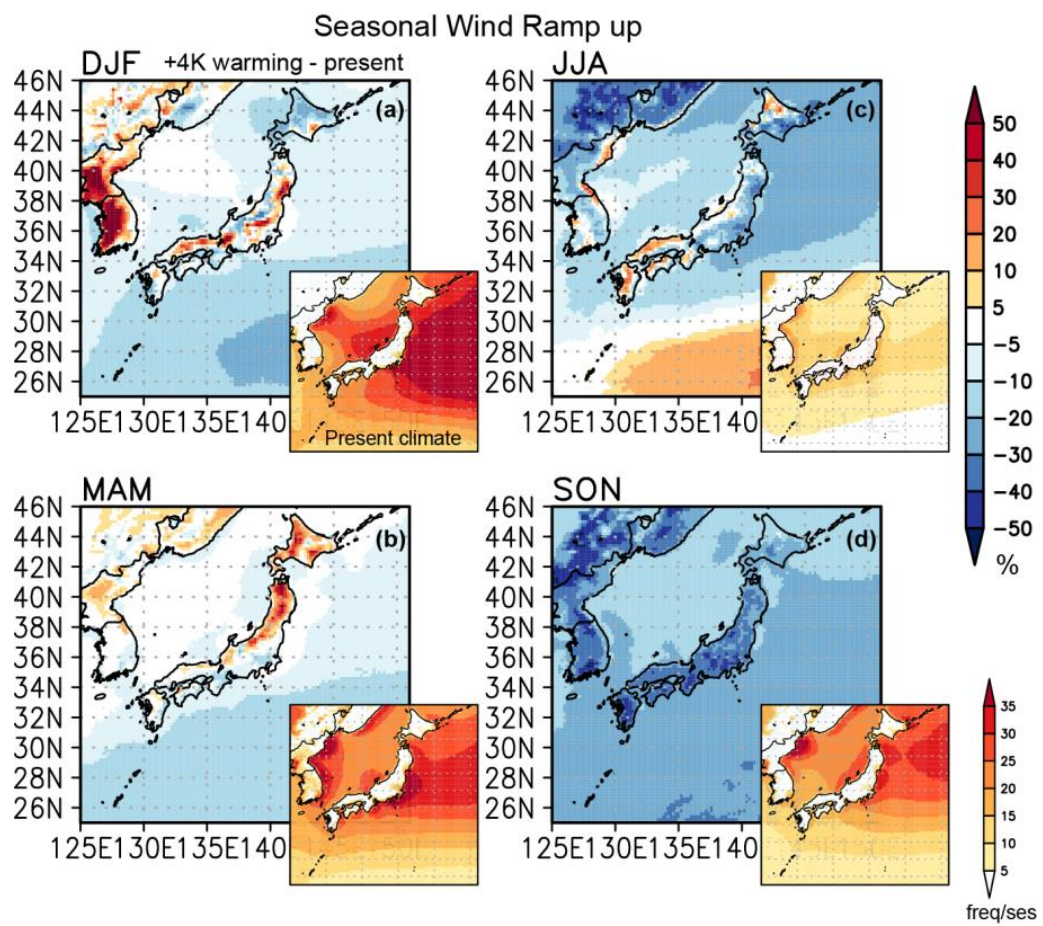

Figure 7. Seasonal evolution of wind ramp-up events in present (inset) and future climate simulations for (a) December-January-February, (b) March-April-May, (c) June-July-August, and (d) SeptemberOctober-November. 


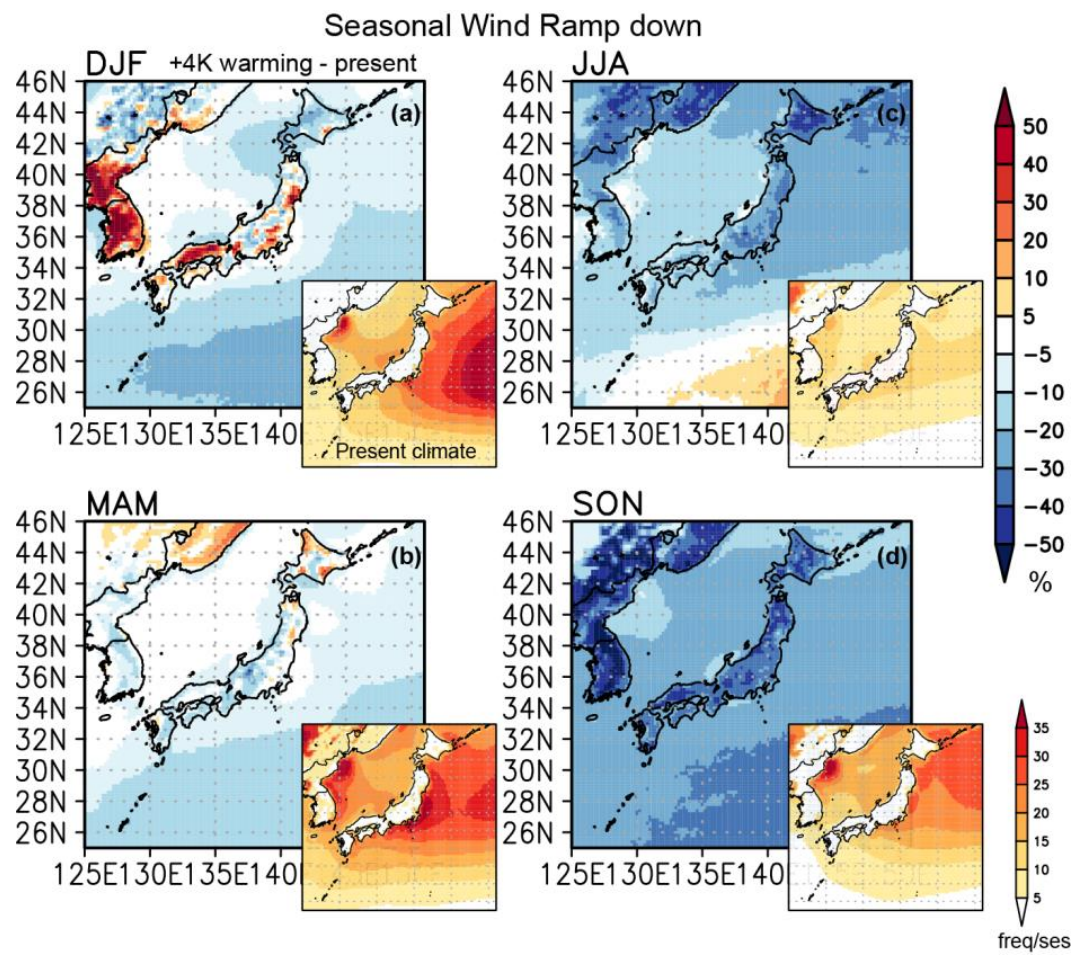

Figure 8. Seasonal evolution of wind ramp-down events in present (inset) and future climate simulations for (a) December-January-February, (b) March-April-May, (c) June-July-August, and (d) SeptemberOctober-November.

\section{Frequency Change in Weather Patterns}

It is conceivable that future changes in the occurrence frequency of WPs could affect the analysis results, i.e., changes in wind power resources and ramps between the $+4 \mathrm{~K}$ warming and present climate simulations. We used the SOM method to analyze this for winter and fall to determine what meteorological factors could contribute to changes in wind resources. These seasons were selected because winter is the most important season for wind energy while fall contains the largest responses to global warming. We applied SOM separately to the SLP during winter (December-January-February) and fall (September-October-November).

First, we assessed the climatological characteristics of atmospheric circulation and its future change around the study area for these seasons (Figure 9). During winter, large-scale circulation around Japan is strongly influenced by the mid-latitude East Asian winter monsoon that is characterized by cold air outbreaks originating from strong zonal gradients of pressure between the Aleutian Low and the Siberian High, which significantly influence local weather systems. In addition, the Japan Sea cyclone track and the southern coastal cyclone track (high activity regions of synoptic-scale transient eddies) are located over Japan during the boreal winter. Fall weather is characterized by fine autumn days and typhoons. Anticyclones carried by westerlies from the Asian mainland to the Japanese islands cause calm, sunny days. Typhoon season runs from August to mid-October, peaking in September in the Pacific Ocean. Typhoons tend to impact the eastern coast of southwestern Japan, producing abundant rainfall in a relatively short time and making fall a second rainy season in this area.

In the $+4 \mathrm{~K}$ future climate simulations, the zonal gradient weakened during winter. A high-pressure anomaly was centered east of Japan (around $160^{\circ} \mathrm{E}$ ) and climatological northeasterly winds weakened in this region. In northern Japan, where the wind direction shifted to easterly, changes in wind speed were less apparent. As for fall, a weakened climatological pressure gradient was also found, but not as clearly as in winter. The meridional gradient was slightly weakened in northern Japan. The easterly wind anomalies over Japan can be regarded as weakened climatological westerlies. 
(a) Present climate: DJF

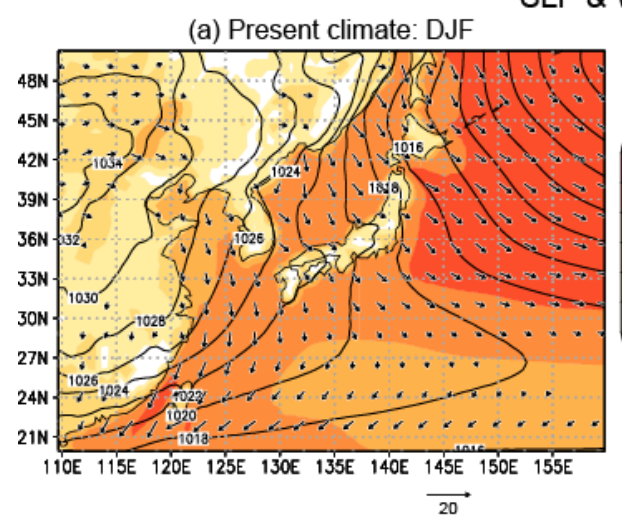

SLP \& Wind speed
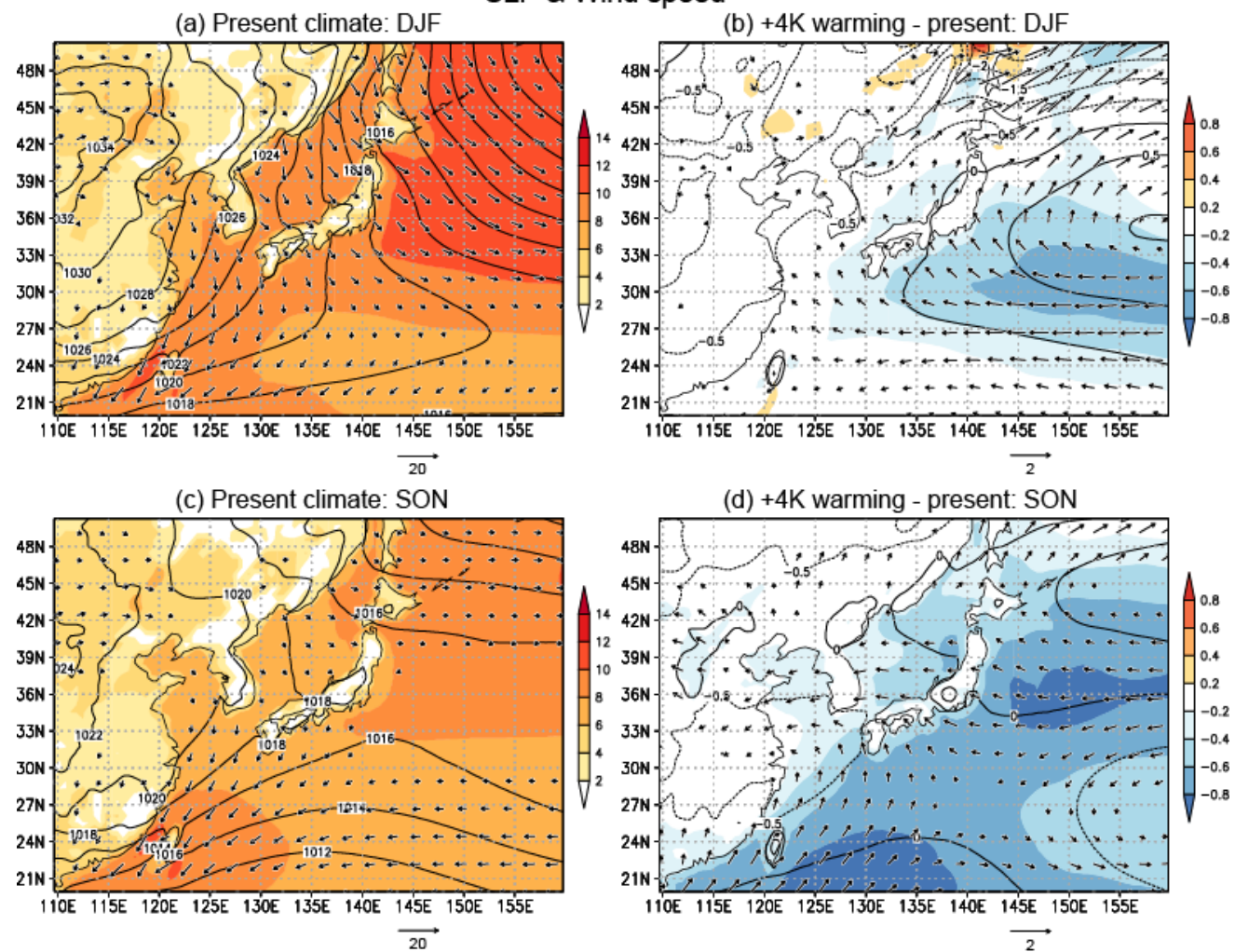

Figure 9. Climatology of seasonal-mean surface wind speed $(\mathrm{m} / \mathrm{s})$ and sea level pressure (SLP, $\mathrm{hPa})$ with horizontal wind vectors $(\mathrm{m} / \mathrm{s})$ for $(\mathbf{a}, \mathbf{b})$ December-January-February and $(\mathbf{c}, \mathbf{d})$ SeptemberOctober-November obtained from the d4PDF-GCM (general circulation models), with differences in climatology between the $+4 \mathrm{~K}$ projection and present climate simulations.

The SOM analysis for winter classified synoptic-scale WPs of SLP around Japan according to 400 nodes (Figure 10). The WPs in relation to strong SLP gradients are distributed in the upper right to bottom left portions of the SOM. It is conceivable that a future change in the occurrence frequency of the WPs could affect the analysis results. To verify the occurrence frequency and its future change, we also assessed the difference in occurrence frequency (\%) of WPs on the SOM between the $+4 \mathrm{~K}$ and present climate simulations (Figure 11). The nodes denoting significant changes were concentrated in different regions on the SOM: increased WPs mainly occurred in the center-right and the center-left areas, while decreased WPs occurred in the bottom-left to bottom-right areas. As certain clustered WP frequencies changed more predominantly, we selected four clustered patterns as representing the dominant global warming impacts on WP frequency change (WP1-4, Figure 11).

The WPs shown in Figure 12 illustrate the cluster-composited SLP for WP1-4 (the other clusters were not shown here for simplicity). The results clearly show the impact of large-scale conditions on wind power generation. Analyzing rapid wind speed change within a $6 \mathrm{~h}$ time horizon can be helpful for understanding future changes in wind ramp frequencies. The cluster-averaged maximum amplitude of wind speed change from the maximum (minimum) value at -3 to $-1 \mathrm{~h}$ to the minimum (maximum) value at +1 to $+3 \mathrm{~h}$ are also presented in Figure 12 . 


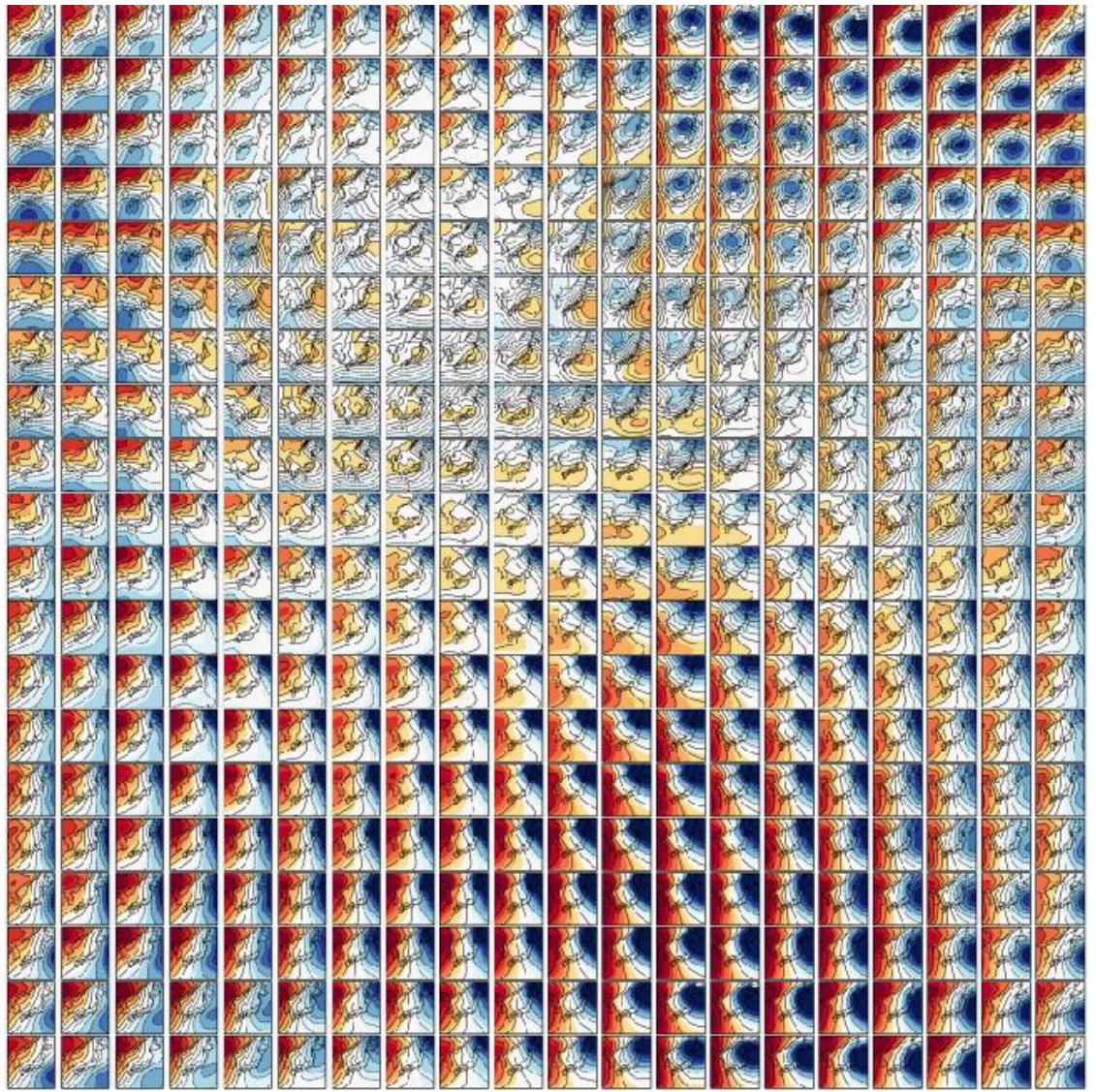

Figure 10. Weather patterns derived from the $20 \times 20$ self-organizing maps (SOMs) non-linear classifications based on sea-level pressure in the d4PDF-GCM for winter. Red (blue) shaded contours indicate relatively high (low) pressure.

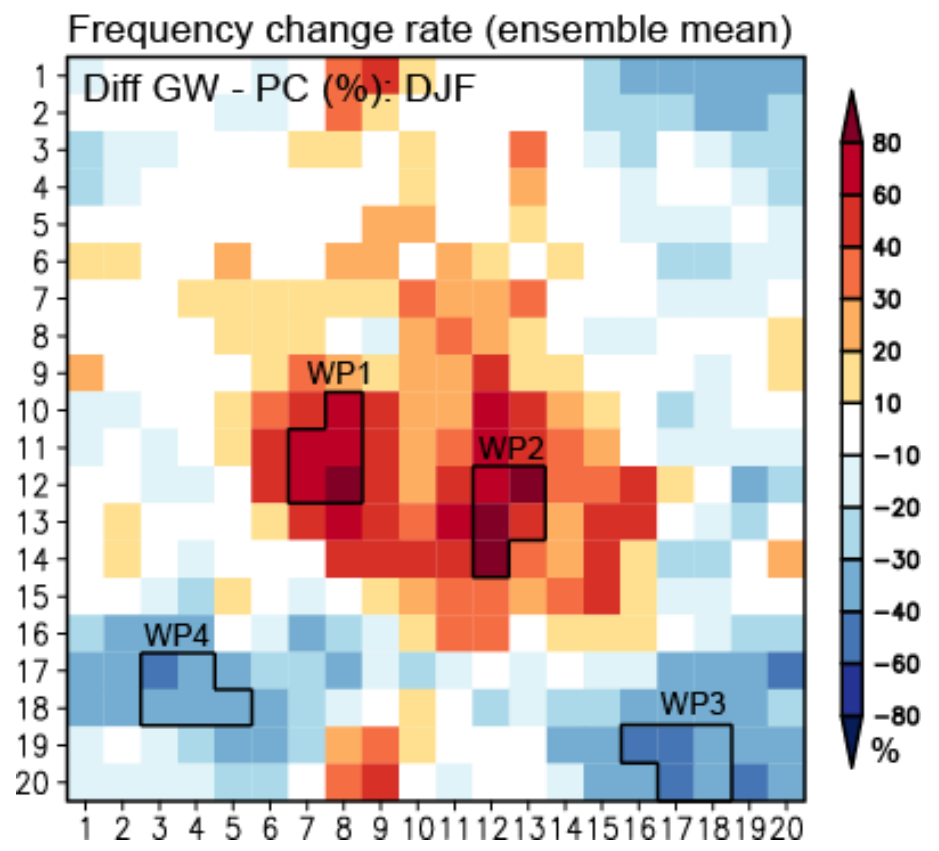

Figure 11. Rate of difference in occurrence frequency for each weather pattern between the $+4 \mathrm{~K}$ future and present climate simulations for winter. Black borders denote the four clusters (WP1-4) of SOM nodes with the greatest changes in occurrence frequency. 


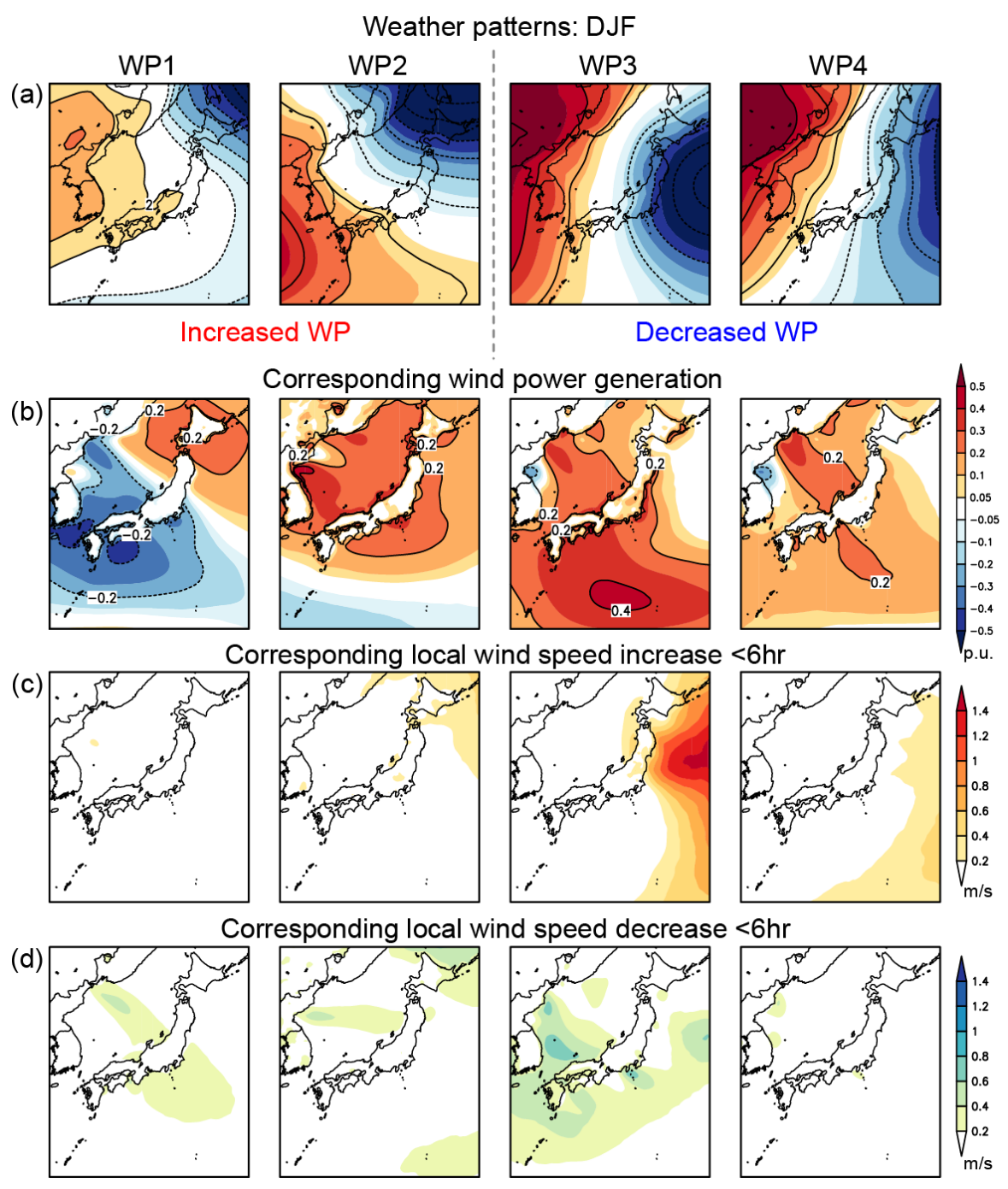

Figure 12. Cluster-composited weather patterns for WP1-4 in December-January-February: (a) relatively high (red) and low (blue) pressure; corresponding (b) wind power generation anomaly "per unit" (p.u.) and (c,d) maximum increase/decrease under 6 hours $(\mathrm{m} / \mathrm{s})$.

The effect of each WP on wind speed and its variability differed by cluster. In WP1, the Siberian high-pressure area extended from west to east over the Sea of Japan and central Japan. In WP2, the meridional gradients of SLP are related to the high (low) SLP over southwestern (northeastern) Japan. In WP3, an extratropical cyclone (very low SLP) was located off the east coast of Japan with strong negative zonal gradients of SLP being caused by enhanced extratropical cyclones in the Kuroshio-Oyashio extension region. In WP4, enhanced high SLP was present in western regions and low SLP in eastern regions; this enhances the clear east-west gradient in climatological conditions. Compared with WP2 and WP3, wind power generation anomalies are weaker in WP4 (Figure 12b). WP3 tends to cause a more rapid increase/decrease in wind speed around Japan than the other weather patterns (Figure 12c-d).

The occurrence frequencies of WP3 and WP4 decreased in the +4K simulations. Since WP3 showed strong wind speed anomalies over Japan (not shown), decreases in its frequency may contribute to decreases in wind resources, especially in southern regions. However, the increased frequency of the windier WP2 made up for the effects of the decreased WP3. The spatially inhomogeneous change (north-south contrast) in wind energy seen in Figures 3 and 4 can be mainly explained by the shift in WP frequency from WP3 to WP2. In the latter, cold air surges cannot reach the subtropical western Pacific. 
We conducted the same analyses as above, but for fall (Figures 13-15). The relatively calm WPs 5-7 showed negative wind speed anomalies with no significant wind variations associated with migratory anticyclones, while WP8 and WP9 were affected by cyclones. In WP8, the northern part of Japan was covered by a strong SLP gradient associated with a low-pressure system located over the Japan Sea, resulting in larger wind power generation and ramps. WP8 represented one of the most severe wind ramping situations of all nine scenarios, showing a high probability of large wind power changes (Figure 15). In WP9, central-eastern Japan was covered by the rear of a low-pressure system in the Pacific. While ramp-up events were highly correlated with the approach of low-pressure systems, ramp-down-dominated WPs were related to the behavior of high-pressure systems extending from the west of Japan [11], such as WP9.

In the future climate experiment, the number of intense cyclones significantly increased whereas the number of total cyclones significantly decreased, similar to the results obtained from the CMIP3 models themselves [48]. In d4PDF, the number of typhoons was also reduced significantly [49], resulting from the decrease in the windy WPs. During fall, the occurrence frequency of windy WPs (WP8 and WP9) decreased about 40\% in the $+4 \mathrm{~K}$ simulations while clear and calm WPs increased. Since the former affected most of the region, their decrease in frequency may correspond with the decrease in regional wind energy potential. In addition, the decreasing WPs (WP8 and WP9) were linked to both ramp-up and ramp-down events. Therefore, during fall, a decrease in low-pressure systems can be the main cause of future decreases and short-term variations in wind power generation.

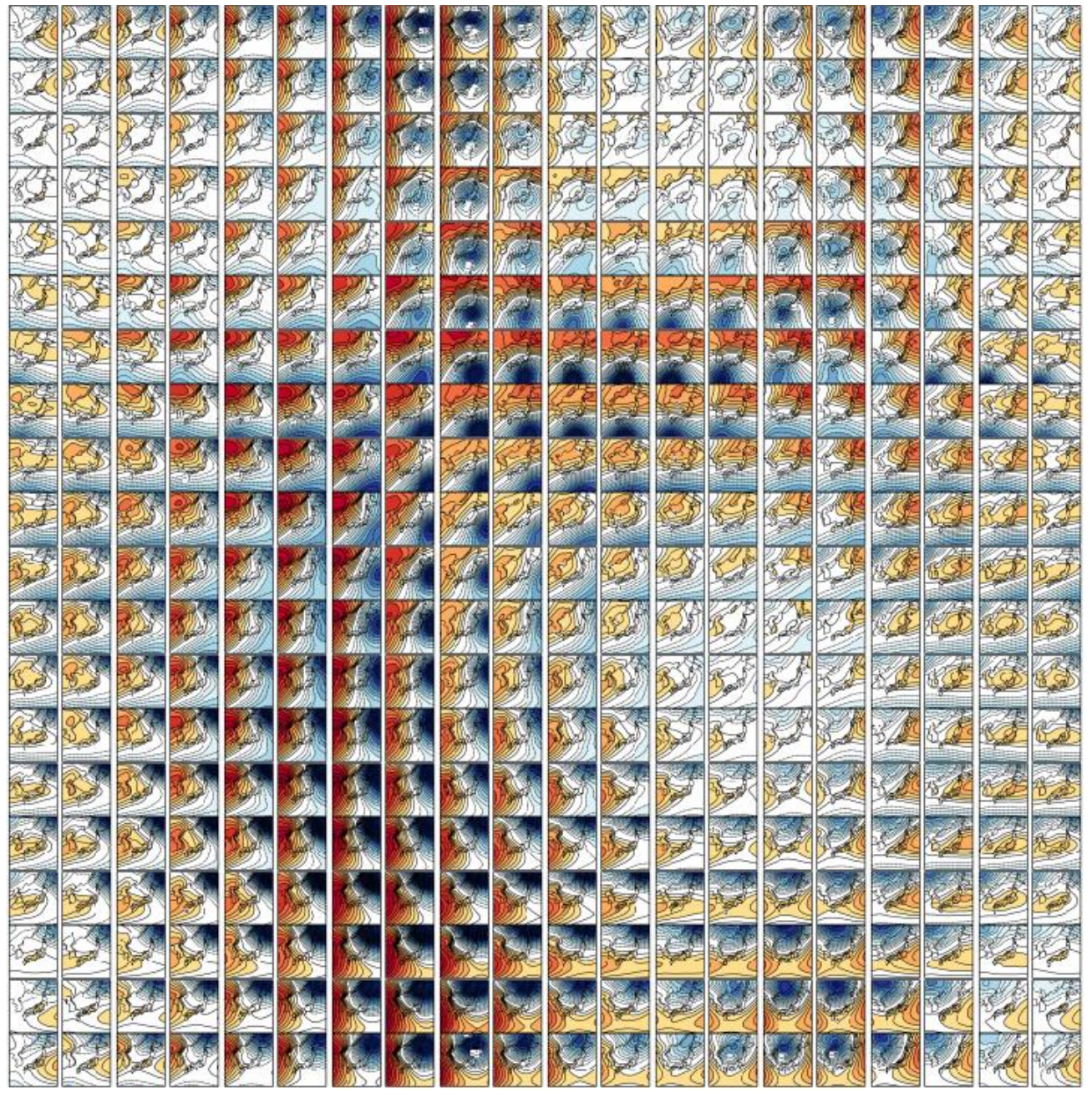

Figure 13. Weather patterns derived from the $20 \times 20$ SOM non-linear classifications based on sea-level pressure in the d4PDF-GCM for fall. Red (blue) shaded contours indicate relatively high (low) pressure. 
Frequency change rate (ensemble mean)

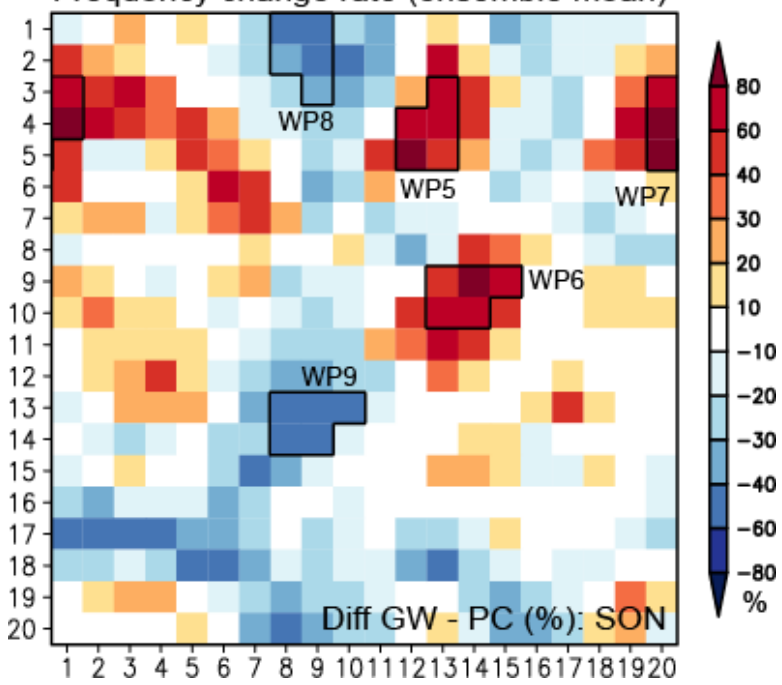

Figure 14. Rate of difference in occurrence frequency for each weather pattern between the $+4 \mathrm{~K}$ future and present climate simulations for fall. Black borders denote the clusters (WP5-9) of SOM nodes with the greatest changes in occurrence frequency.
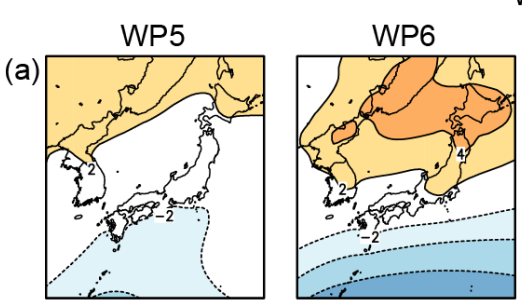

eather patterns: SON
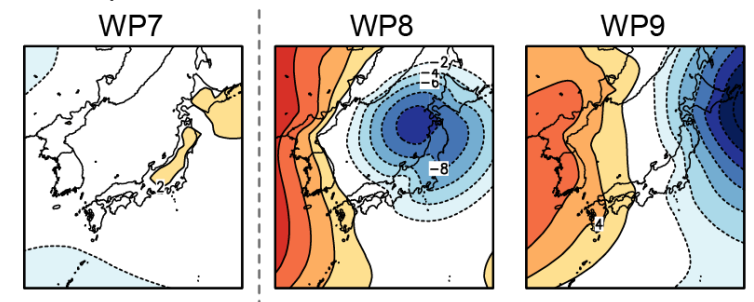

Increased WP

Decreased WP

(b)
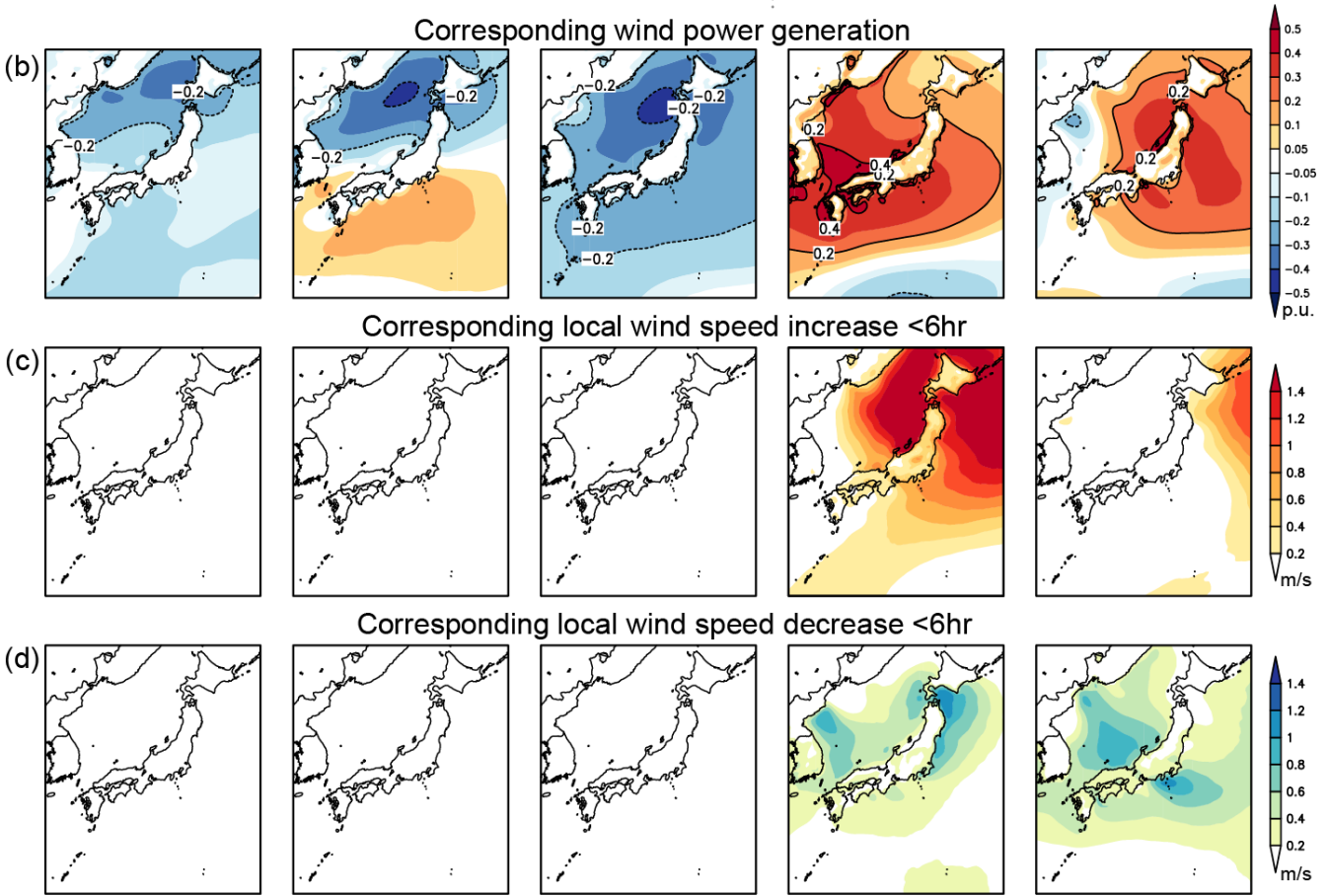

Figure 15. Cluster-composited weather patterns for WP5-9 in September-October-November: (a) relatively high (red) and low (blue) pressure; corresponding (b) wind power generation anomaly (p.u.) and $(\mathrm{c}, \mathrm{d})$ maximum increase/decrease under 6 hours $(\mathrm{m} / \mathrm{s})$. 


\section{Discussion}

\subsection{Dynamical and Thermodynamic Contributions}

Above, we only showed the changes in frequency of synoptic WPs. To explore this further, here we discuss the impact of future changes in wind energy resources by separating the dynamical and thermodynamic contributions using the SOM-CCA (Figure 16). During the winter, large-scale meridional asymmetric changes (intensification in the north and weakening in the south) in wind energy resources come mainly from the dynamical effect, while changes over land come from the thermodynamic contribution. This may relate to the reduction in snow depth during the future climate, resulting in an increase in vertical momentum entrainment via changes in the vertical temperature profile over Japan. During fall, the dynamical contribution is larger while thermodynamics also contribute to the reduction of wind energy, especially in the southern part of Japan. The thermodynamics changes (factors excluding circulation frequency change) may come from changes in surface local properties that can affect downward vertical momentum flux through changes in atmospheric stability/boundary-layer condition and the position of the jet stream in the upper levels of the atmosphere.

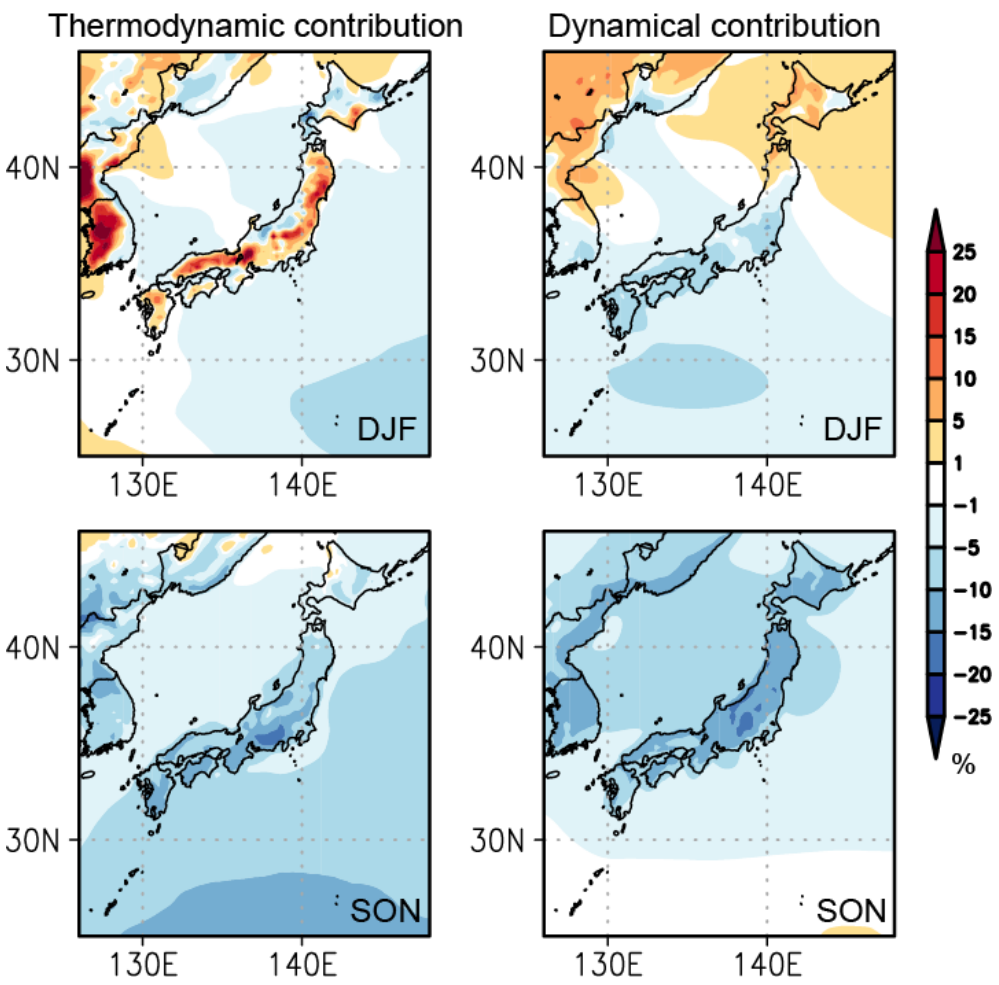

Figure 16. Decomposition of future changes in wind energy (presented in Figure 4) during DJF (top) and SON (bottom) into contributions from (left) thermodynamics and (right) dynamics using the SOM-CCA (circulation analog method).

\subsection{Diversity from Model SST}

Several studies have shown that changes in wind energy potentials are sensitive to the choice of climate models and can be affected by the model's initial conditions and internal variability $[3,6,50]$. Additionally, future projections of synoptic activity (e.g., storm tracks) may differ strongly between individual climate models [51-53], which could be attributed to large differences in the response to surface conditions between models. To verify the impact of model SST diversity in d4PDF $+4 \mathrm{~K}$ simulations, we assessed changes in wind energy production for each model SST (Figure 17). As expected from the large differences in climatology, the sensitivity of each WP to projected warming differed between the model SSTs. Such differences could be related to the spatial distribution of 
large-scale climatology that impacts water vapor advection from the large scale to the synoptic scale. Therefore, our findings suggest that projected changes in wind energy are likely to be affected by SST warming patterns in the future. Further studies are needed to more accurately estimate future wind energy resources in Japan.

\section{Annual Wind Power Production $+4 \mathrm{~K}$ warming - present}

(a) CCSM4

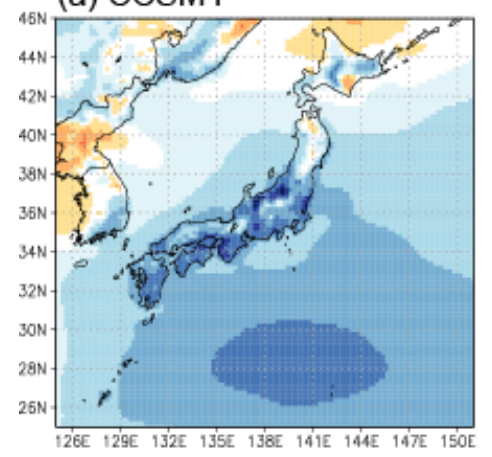

(d) MIROC5

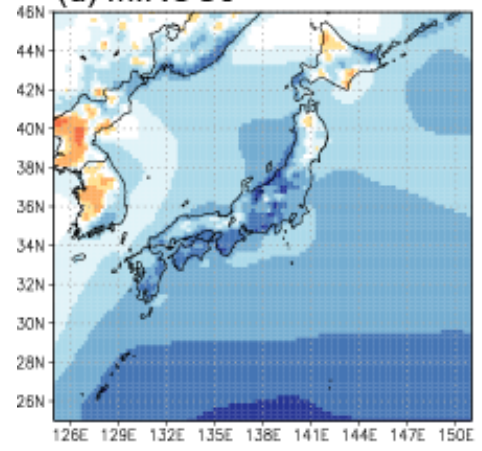

(b) HadGEM2-AO

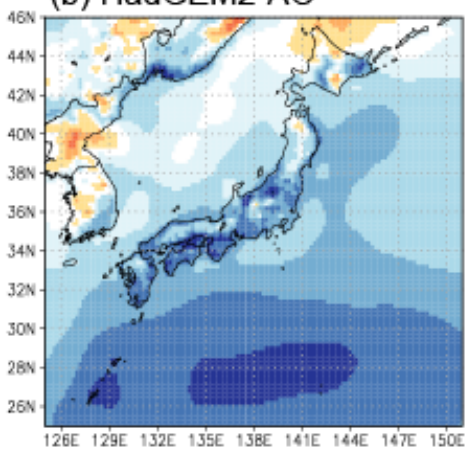

(e) MPI-ESM-MR

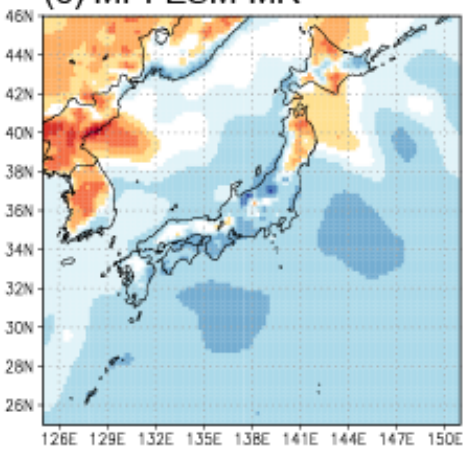

(c) GFDL-CM3

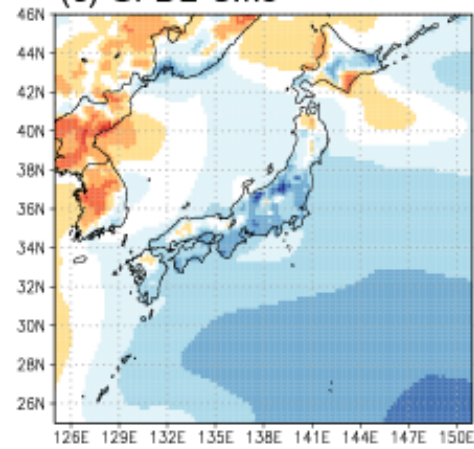

(f) MRI-CGCM3

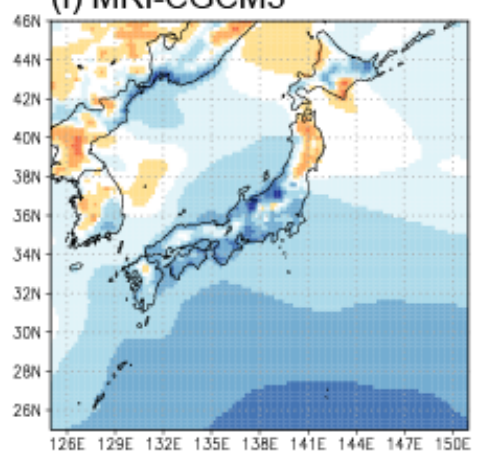

Figure 17. Difference in annual capacity factor between future $+4 \mathrm{~K}$ and present climate simulations using the different six SST anomalies obtained from CMIP5 models (a) CCSM4, (b) HadGEM2-AO, (c) GFDL-CM3, (d) MIROC5, (e) MPI-ESM-MR, and (f) MRI-CGCM3.

\section{Conclusions}

Understanding the impacts of global warming on the wind power sector is important for future energy management in Japan. In addition to forecasting the short-term variability of wind power output [13-15], evaluating wind power potential is an important subject in wind power management $[3,9,10,54,55]$ since this significantly affects the cost of wind energy [8]. While these impacts have been paid increasing attention recently, they are still not well understood. By using state-of-the-art global warming large ensemble data (d4PDF), we were able to analyze possible changes in wind energy resources and ramp events under future $+4 \mathrm{~K}$ conditions with a focus on regional-scale changes. Changes in wind resources and variability in Japan were estimated using $20 \mathrm{~km}$ downscaling simulation data (d4PDF-RCM), projecting a decrease in annual wind energy resources around Japan in future decades as suggested by [9], although the projected changes were relatively small $(-4.3 \%$, when compared with the same domain: $128^{\circ} \mathrm{E}-142^{\circ} \mathrm{E}, 30^{\circ} \mathrm{N}-42^{\circ} \mathrm{N}$ ).

In regional terms, our results projected decreasing wind energy resources over southern and central Japan. In seasonal terms, the changes were much more apparent: a slight increase in wind energy potential was identified for northern Japan from winter to spring with a decrease in most regions from summer to fall. The impact of global warming on wind energy was largest during fall. However, in winter, no clear change in wind energy potential could be identified although the wind direction was significantly altered. 
In terms of wind energy variability, we projected significant decreases in ramp-down frequencies in the $+4 \mathrm{~K}$ simulation. These changes were more remarkable over onshore areas in western and central-eastern Japan, reaching up to $-15 \%$, indicating a considerable change in the ramp frequency. The global warming impact on wind ramping was also largest during fall.

Most changes in wind energy were connected to alterations in the large-scale basic state (SLP and surface wind) and synoptic activity over Japan. We examined the impacts of global warming on wind energy by classifying the SLP field using the SOM method, confirming that wind power generation and ramp events were significantly associated with changes in frequency of synoptic WPs. During fall, the decrease in the low-pressure system was the main cause of the future decrease in wind energy. In contrast, in winter, the large-scale basic-state change is the main cause of future changes in wind energy. These findings are important for the future planning of reliable energy networks and supplies in Japan, which should be prepared for a reduction in wind energy potential under future climate conditions while likely experiencing decreasing potential for wind ramp events. Although these are the results of a massive ensemble experiment that has never been conducted before, they still represent a single model result. To obtain more accurate projections, the results should be verified using multi-model dynamical downscaling data.

To confirm the SOM results, we also used the SOM-compressed CCA (SOM-CCA) to illustrate the importance of contributions from dynamics by separating the dynamic and thermodynamic components of changes in wind energy resources. Major changes could be attributed to the changes in frequency of WPs (dynamics), consistent with the results in Section 4. We also found diverse results among the simulations in response to different model SST anomalies. Climate variability has a marked impact on the frequency of wind ramp events over Japan [11]. In particular, El Niño and La Niña events correspond to different WPs in the western Pacific climate [44]. Thus, future changes in tropical SST patterns can affect WP frequency via the Pacific-Japan pattern [25], ENSO transitions [56], and Indian Ocean SSTs [23-25]. To validate the relationship between future changes in the tropical Indo-Pacific SST and WPs around Japan, future research should investigate interannual variations in wind energy and related WPs using d4PDF and its consistency with the projected tropical SST changes.

Our results provide an interesting perspective on the impact of climate change projections on the wind energy sector in Japan. Furthermore, we suggest that WP classifications can be used as a bridging tool between general circulation and regional climate models. SOMs have been shown to be robust for analyses of synoptic WPs corresponding with wind energy production and ramp events. We also demonstrated the use of compressed atmospheric circulation analogs to illustrate the thermodynamic and dynamic contributions. We conclude that this technique can be an effective tool for the analysis of WP-dependent weather events, with potential to be applied to climate change impact assessment studies.

Funding: This research was funded by JSPS KAKENHI, grant number JP 17K18426 and partly supported by the "Research and development projects on power system output fluctuation-related technology" of the New Energy and Industrial Technology Development Organization (NEDO).

Acknowledgments: We express thanks to Y. Takeyama, D. Nohara, and S. Kadokura for their constructive discussions. This study utilized the database for Policy Decision making for Future climate change (d4PDF), which was produced under the SOUSEI program.

Conflicts of Interest: The authors declare no conflict of interest.

\section{References}

1. Mizuno, E. Overview of wind energy policy and development in Japan. Renew Sustain. Energy Rev. 2014, 40, 999-1018. [CrossRef]

2. Pryor, S.C.; Barthelmie, R.J. Climate change impacts on wind energy: A review. Renew Sustain. Energy Rev. 2010, 14, 430-437. [CrossRef]

3. Pryor, S.; Barthelmie, R.J.; Clausen, N.E.; Drews, M.; MacKellar, N.; Kjellström, E. Analyses of possible changes in intense and extreme wind speeds over northern Europe under climate change scenarios. Clim. Dyn. 2012, 38, 189-208. [CrossRef] 
4. Nolan, P.; Lynch, P.; McGrath, R.; Semmler, T.; Wang, S. Simulating climate change and its effects on the wind energy resource of Ireland. Wind Energy 2012, 15, 593-608. [CrossRef]

5. Hueging, H.; Haas, R.; Born, K.; Jacob, D.; Pinto, J.G. Regional changes in wind energy potential over Europe using regional climate model ensemble projections. J. Appl. Meteorol. Climatol. 2013, 52, 903-917. [CrossRef]

6. Tobin, I.; Vautard, R.; Balog, I.; Breon, F.-M.; Jerez, S.; Ruti, P.M.; Thais, F.; Vrac, M.; Yiou, P. Assessing climate change impacts on European wind energy from ENSEMBLES high-resolution climate projections. Clim. Change 2015, 128, 99-112. [CrossRef]

7. Reyers, M.; Moemken, J.; Pinto, J.G. Future changes of wind energy potentials over Europe in a large CMIP5 multi-model ensemble. Int. J. Climatol. 2015, 36, 783-796. [CrossRef]

8. Hdidouan, D.; Staffell, I. The impact of climate change on the levelised cost of wind energy. Renew Energy 2017, 101, 575-592. [CrossRef]

9. Karnauskas, K.B.; Lundquist, J.K.; Zhang, L. Southward shift of the global wind energy resource under high carbon dioxide emissions. Nat. Geosci. 2017, 11, 38-43. [CrossRef]

10. Brayshaw, D.J.; Troccoli, A.; Fordham, R.; Methven, J. The impact of large scale atmospheric circulation patterns on wind power generation and its potential predictability: A case study over the UK. Renew Energy 2011, 36, 2087-2096. [CrossRef]

11. Ohba, M.; Kadokura, S.; Nohara, D. Impacts of synoptic circulation patterns on wind power ramp events in East Japan. Renew Energy 2016, 96, 591-602. [CrossRef]

12. Yoshida, K.; Hayasaki, N.; Ohba, M.; Nohara, D.; Ogasawara, N.; Okada, M.; Mori, Y.; Ogimoto, K.; Kataoka, K. Analysis of meteorological factors of wind power ramps in Hokkaido and Tohoku area. IEEJ Trans. Power Energy 2017, 137, 71-78. [CrossRef]

13. Ohba, M.; Nohara, D.; Kadokura, S. Medium-range probabilistic forecasts of wind power generation and ramps in Japan based on a hybrid ensemble. Atmosphere 2018, 9, 423. [CrossRef]

14. Fujimoto, Y.; Takahashi, Y.; Hayashi, Y. Alerting to rare large-scale ramp events in wind power generation. IEEE Tran. Sustain. Energ 2019, 10, 55-65. [CrossRef]

15. Marquis, M.; Wilczak, J.; Ahlstrom, M.; Sharp, J.; Stern, A.; Smith, J.C.; Calvert, S. Forecasting the wind to reach significant penetration levels of wind energy. Bull. Am. Meteorol. Soc. 2011, 92, 1159-1171. [CrossRef]

16. Kozai, K.; Ohsawa, T.; Shimada, S.; Takeyama, Y.; Hasager, C.B.; Badger, M. Comparison of Envisat/ASARestimated offshore wind resource maps around Shirahama with those from mesoscale models MM5 and WRF. In Proceedings of the European Offshore Wind 2009, Stockholm, Sweden, 14-16 September 2009; p. 7.

17. Shimada, S.; Ohsawa, T. Accuracy and characteristics of offshore wind speeds simulated by WRF. SOLA 2011, 7, 21-24. [CrossRef]

18. Shimada, S.; Ohsawa, T.; Kogaki, T.; Steinfeld, G.; Heinemann, D. Effects of sea surface temperature accuracy on offshore wind resource assessment using a mesoscale model. Wind Energy 2015, 18, 1839-1854. [CrossRef]

19. Takeyama, Y.; Ohsawa, T.; Kozai, K.; Hasager, C.B.; Badger, M. Effectiveness of WRF wind direction for retrieving coastal sea surface wind from synthetic aperture radar. Wind Energy 2013, 16, 865-878. [CrossRef]

20. Ohsawa, T.; Shimada, S.; Tambke, J.; Lange, B. A study on effective usage of mesoscale model for accurate offshore wind simulation. In Proceedings of the European Offshore Wind Conference 2009, Stockholm, Sweden, 14-16 September 2009; p. 10.

21. Ohsawa, T.; Tubouchi, N.; Niwa, R.; Tanemoto, J.; Shimada, S.; Takeyama, Y. Characteristics of offshore wind speed simulated with WRF in the seas around Japan. In Proceedings of the European Offshore Wind Conference 2011, Amsterdam, The Netherlands, 29 November-1 December 2011; p. 9.

22. Ohsawa, T.; Orita, T.; Kozai, K.; Shimada, S.; Steinfeld, G.; Heinemann, D. Accuracy evaluation of hub-height wind speeds estimated from scatterometer and mesoscale model. In Proceedings of the EWEA OFFSHORE 2015, Copenhagen, Denmark, 10-12 March 2015; p. 7.

23. Ohba, M.; Ueda, H. A role of zonal gradient of SST between the Indian Ocean and the Western Pacific in localized convection around the Philippines. SOLA 2006, 2, 176-179. [CrossRef]

24. Xie, S.P.; Hu, K.; Hafner, J.; Tokinaga, H.; Du, Y.; Huang, G.; Sampe, T. Indian Ocean capacitor effect on Indo-western Pacific climate during the summer following El Nino. J. Clim. 2009, 22, 730-747. [CrossRef]

25. Kosaka, Y.; Xie, S.P.; Lau, N.C.; Vecchi, G.A. Origin of seasonal predictability for summer climate over the Northwestern Pacific. Proc. Natl. Acad. Sci. USA 2013, 110, 7574-7579. [CrossRef] [PubMed]

26. Mizuta, R.; Nurata, A.; Ishii, M. Over 5000 years of ensemble future climate simulations by $60 \mathrm{~km}$ global and $20 \mathrm{~km}$ regional atmospheric models. Bull. Amer. Meteor. Soc. 2017, 98, 1383-1398. [CrossRef] 
27. Ohba, M.; Nohara, D.; Ueda, H. Simulation of asymmetric ENSO transition in WCRP CMIP3 multi-model experiments. J. Clim. 2010, 23, 6051-6067. [CrossRef]

28. Ohba, M.; Sugimoto, S. Differences in climate change impacts between weather patterns: Possible effects on spatial heterogeneous changes of future extreme rainfall. Clim. Dyn. 2018, 52, 4177-4191. [CrossRef]

29. Kayaba, N.; Yamada, T.; Hayashi, S.; Onogi, K.; Kobayashi, S.; Yoshimoto, K.; Kamiguchi, K.; Yamashita, K. Dynamical regional downscaling using the JRA-55 reanalysis (DSJRA-55). SOLA 2016, 12, 1-5. (In Japanese) [CrossRef]

30. Kobayashi, S.; Ota, Y.; Harada, Y.; Ebita, A.; Moriya, M.; Onoda, H.; Onogi, K.; Kamahori, H.; Kobayashi, C.; Endo, H.; et al. The JRA-55 reanalysis: General specifications and basic characteristics. J. Meteor. Soc. Japan 2015, 93, 5-48. [CrossRef]

31. Holttinen, H. Hourly wind power variations in the Nordic countries. Wind Energy 2004, 8, 73-95. [CrossRef]

32. Laslett, D.; Creagh, C.; Jennings, P. A simple hourly wind power simulation for the south-west region of Western Australia using MERRA data. Renew Energy 2016, 96, 1003-1014. [CrossRef]

33. Drew, D.R.; Cannon, D.J.; Brayshaw, D.J.; Barlow, J.F.; Coker, P.J. The impact of future offshore wind farms on wind power generation in Great Britain. Resources 2015, 4, 155-171. [CrossRef]

34. Cannon, D.J.; Brayshaw, D.J.; Methven, J.; Coker, P.J.; Lenaghan, D. Using reanalysis data to quantify extreme wind power generation statistics: A 33 year case study in Great Britain. Renew Energy 2015, 75, 767-778. [CrossRef]

35. Klink, K. Atmospheric circulation effects on wind speed variability at turbine height. J. Appl. Meteorol. Climatol. 2007, 46, 445-456. [CrossRef]

36. Gibson, P.B.; Cullen, N.J. Synoptic and sub-synoptic circulation effects on wind resource variability-A case study from a coastal terrain setting in New Zealand. Renew Energy 2015, 78, 253-263. [CrossRef]

37. Hamlington, B.D.; Hamlington, P.E.; Collins, S.G.; Alexander, S.R.; Kim, K.Y. Effects of climate oscillations on wind resource variability in the United States. Geophys. Res. Lett. 2015, 42, 145e152. [CrossRef]

38. Kohonen, T. Self-organized formation of topologically correct feature maps. Biol. Cybern. 1982, 43, 59-69. [CrossRef]

39. Ohba, M.; Kadokura, S.; Nohara, D.; Toyoda, Y. Rainfall downscaling of weekly ensemble forecasts using self-organizing maps. Tellus A 2016b, 68, 29293. [CrossRef]

40. Cassano, J.J.; Uotila, P.; Lynch, A.H.; Cassano, E.N. Predicted changes in synoptic forcing of net precipitation in large Arctic river basins during the 21st century. J. Geophys. Res. 2007, 112, G04S49. [CrossRef]

41. Gibson, P.B.; Perkins-Kirkpatrick, S.E.; Renwick, J.A. Projected changes in synoptic weather patterns over New Zealand examined through self-organizing maps. Int. J. Climatol. 2016, 36, 3934-3948. [CrossRef]

42. Vesanto, J.; Alhoniemi, E. Clustering of the self-organizing map. IEEE Trans. Neural. Netw. 2000, 11, 586-600. [CrossRef]

43. Leloup, J.A.; Lachkar, Z.; Boulanger, J.P.; Thiria, S. Detecting decadal changes in ENSO using neural networks. Clim. Dyn. 2007, 28, 147-162. [CrossRef]

44. Ohba, M.; Kadokura, S.; Yoshida, Y.; Nohara, D.; Toyoda, Y. Anomalous weather patterns in relation to heavy precipitation events in Japan during the Baiu season. J. Hydrometeorol. 2015, 16, 688-701. [CrossRef]

45. Ward, J.H., Jr. Hierarchical grouping to optimize an objective function. J. Am. Stat. Assoc. 1963, 58, $236-244$. [CrossRef]

46. Van den Dool, H.M.; Huang, J.; Fan, Y. Performance and analysis of the constructed analogue method applied to U.S. soil moisture over 1981-2001. J. Geophys. Res. 2003, 108, 8617. [CrossRef]

47. Deser, C.; Terray, L.; Phillips, A.S. Forced and internal components of winter air temperature trends over North America during the past 50 years: Mechanisms and implications. J. Clim. 2016, 29, 2237-2258. [CrossRef]

48. Mizuta, R.; Matsueda, M.; Endo, H.; Yukimoto, S. Future change in extratropical cyclones associated with change in the upper troposphere. J. Clim. 2011, 24, 6456-6470. [CrossRef]

49. Yoshida, K.; Sugi, M.; Mizuta, R.; Murakami, H.; Ishii, M. Future changes in tropical cyclone activity in high-resolution large-ensemble simulations. Geophys. Res. Lett. 2017, 44, 9910-9917. [CrossRef]

50. Pryor, S.C.; Schoof, J.T.; Barthelmie, R.J. Empirical downscaling of wind speed probability distributions. J. Geophys. Res. 2005, 110, D19109. [CrossRef]

51. Harvey, B.J.; Shaffrey, L.C.; Woollings, T.J.; Zappa, G.; Hodges, K.I. How large are projected 21st century storm track changes? Geophys. Res. Lett. 2012, 39, L18707. [CrossRef] 
52. Harvey, B.J.; Shaffrey, L.C.; Woollings, T.J. Equator-to-pole temperature differences and the extra-tropical storm track responses of the CMIP5 climate models. Clim. Dyn. 2014, 43, 1171-1182. [CrossRef]

53. Zappa, G.; Shaffrey, L.C.; Hodges, K.I.; Sansom, P.G.; Stephenson, D.B. A multimodel assessment of future projections of North Atlantic and European extratropical cyclones in the CMIP5 climate models. J. Clim. 2013, 26, 5846-5862. [CrossRef]

54. Archer, C.L.; Jacobson, M.Z. Evaluation of global wind power. J. Geophys. Res. 2005, 110, D12110. [CrossRef]

55. Evans, J.P.; Kay, M.; Prasad, A.; Pitman, A. The resilience of Australian wind energy to climate change. Environ. Res. Lett. 2018, 13, 024014. [CrossRef]

56. Ohba, M.; Ueda, H. Role of Nonlinear Atmospheric Response to SST on the Asymmetric Transition Process of ENSO. J. Clim. 2009, 22, 177-192. [CrossRef]

(C) 2019 by the author. Licensee MDPI, Basel, Switzerland. This article is an open access article distributed under the terms and conditions of the Creative Commons Attribution (CC BY) license (http://creativecommons.org/licenses/by/4.0/). 